\title{
El mundo funerario calcolítico de la Región de Madrid ${ }^{1}$
}

\author{
Raquel Aliaga Almela. \\ Departamento de Prehistoria y Arqueología de la UAM
}

\begin{abstract}
Resumen
El presente trabajo tiene como objetivo analizar el panorama arqueológico funerario de la región de Madrid en el III milenio a. C., un panorama que no resulta fácil de estudiar por la escasez de hallazgos y datos publicados, pero que poco a poco va ampliándose con nuevos descubrimientos.

El periodo que nos ocupa es muy amplio, puesto que se desarrolla a lo largo de algo más de 1000 años, y las formas de enterramiento que tienen lugar durante ese tiempo son muy diversas. Las diferencias entre unas y otras pueden deberse cambios acontecidos a lo largo del tiempo como resultado de una evolución cronológica de las pautas funerarias de los grupos humanos que habitaban la región, pero tampoco podemos descartar que coexistan en el mismo momento formas de enterramiento distintas, como parece deducirse de los últimos datos aportados por Camino de las Yeseras.
\end{abstract}

Palabras clave: Calcolítico, Madrid, Mundo funerario, Sociedad

\section{Résumé}

Ce travail a comme finalité l'étude du monde funéraire de la région de Madrid durant le III millenium a. C., avec tous les problèmes qui a cette question pour la pénurie de découverts publiés.

Le Chalcolithique est un période très large, avec une durée de plus de 1000 ans, et les formes funéraires que nous documentons pour ce temps son très variées. Les différences entre tipes de tombes peuvent être conséquence de changes arrivés au long du temps comme résulté d'une évolution chronologique de les règles funéraires qui avaient les groupes humaines qui habitent la région, mais nous ne pouvons écarter que ces pratiques soient contemporaines, comme indiquent les nouvelles données apportées par Camino de las Yeseras.

Mots clef: Chalcolithique, Madrid, Monde funéraire, Société.

\section{Panorama general del mundo funera- RIO DEL III MILENIO A. C. EN LA REgIÓN DE MADRID}

El primero de los problemas con el que nos encontramos a la hora de analizar las prácticas

1 Este artículo es resultado del trabajo de investigación llevado a cabo dentro de los proyectos Economía y ritualidad durante el III milenio a. C. en la Comunidad de Madrid (C6606-UAM/HUM0469/1003140025) dirigido por la pro- funerarias del III milenio a. C. es la falta de dataciones absolutas y la escasa validez de la cerámica campaniforme como elemento discriminatorio con valor cronológico.

Tradicionalmente, el Calcolítico Precampa- 
niforme se ha definido por la presencia de formas cerámicas globulares u ovoides, cuencos y algunas fuentes carenadas o de bordes engrosados, y algunos autores lo subdividen a su vez en dos fases: Neolítico Final/Calcolítico Inicial (comienzos del III milenio a. C.) y Calcolítico Pleno (mitad del III milenio a. C.) (Fabián, 1993; Muñoz López-Astilleros, 1999: 93). El calcolítico Campaniforme (finales del III milenio a. C. y principios del II), en cambio, estaría caracterizado por la presencia de la cerámica epónima y por el auge de la metalurgia, si bien, no parece representar grandes cambios con respecto a la fase anterior (Muñoz et al., 1995: 38).

Esta periodización y la definición temporal del Calcolítico en la región de Madrid tiene en su origen diversos problemas, de los cuales, el más importante es la ausencia de criterios tipológicos discriminatorios claros entre el Neolítico Final y el Calcolítico Precampaniforme, y la enorme homogeneidad que presentan gran parte de los materiales cerámicos de esta etapa y la Edad del Bronce. La raíz del problema está en el sistema tipológico tradicional basado en la cerámica decorada como fósil director y en la escasez de muestras de este material dentro del registro arqueológico, ya que porcentualmente representa una mínima parte de toda la producción cerámica, de manera que se identifican como conjuntos campaniformes todos aquellos en los que aparece cerámica campaniforme, y como precampaniformes aquellos en los que no aparece (Díaz-del-Río, 2001: 46), lo que no siempre responde a la realidad.

Esta situación, debido a la total ausencia de dataciones absolutas publicadas realizadas sobre contextos funerarios para la Región de Madrid, a excepción de las de Camino de las Yeseras (Liesau et al., 2008: 99), invalidaba cualquier análisis evolutivo de las prácticas funerarias del III milenio a. C.

Considero, por tanto, conveniente eliminar cualquier connotación cronológica al clasificar las formas funerarias calcolíticas de esta región en enterramientos "campaniformes" y enterramientos "no-campaniformes". Se trata, simplemente, de un sistema de catalogación de los ajuares en función de la ausencia o presencia de este tipo cerámico, sin que ello conlleve una clasificación cronológica, ya que, si bien podemos inferir que los enterramientos con ajuares campaniformes son de un momento relativamente avanzado del
Calcolítico, no podemos situar en el tiempo los conjuntos con cerámicas no-campaniformes.

\section{Los enterramientos no-campaniformes.}

Las prácticas funerarias no-campaniformes de la región de Madrid responden, en principio, a un doble modelo, caracterizado por el enterramiento colectivo en cueva de El Rebollosillo (Díaz-delRío, 2001: 145), Juan Barbero (Martínez Navarrete, 1984) y Pedro Fernández (Sánchez Meseguer, 1979); y la inhumación individual, doble o múltiple en contexto de poblado hallada en Las Fronteras, Valdocarros y Camino de las Yeseras, ya que no contamos con suficientes datos para hablar de megalitos de uso funerario en la región de Madrid adscribibles a esta primera etapa del Calcolítico, a pesar de que, siguiendo a Jiménez Guijarro, existirían varios ejemplos de construcciones de este tipo (Jiménez Guijarro, 2001) al margen del ya conocido Entretérminos, del que sólo conocemos un enterramiento campaniforme.

En la mayor parte de los casos parece existir una clara relación de proximidad entre las zonas de habitación y los enterramientos, que se ubican en las mismas áreas, sin separación alguna, si bien la inexistencia de una estratigrafía vertical clara impide saber si realmente los enterramientos son contemporáneos a la ocupación habitacional de las estructuras adyacentes. No obstante, lo que sí que parece evidente es que la localización de las estructuras funerarias fue respetada por las construcciones posteriores dentro de los asentamientos, y un ejemplo de ello es el caso documentado en Camino de las Yeseras, donde uno de los enterramientos es salvado por el tramo de foso que discurre en las inmediaciones, que realiza un claro quiebro en su trazado para no destruirlo (Liesau et al., 2008: 109).

La asociación entre el mundo de los muertos y el de los vivos es más evidente en los yacimientos de "campos de hoyos" como Las Frontera o Camino de las Yeseras, donde las estructuras de enterramiento se distribuyen entre el resto de unidades negativas, sin que puedan apreciarse si quiera diferencias morfológicas entre unas y otras. Sin embargo, esta relación de proximidad se da también en el caso de las cuevas, ya que en el caso de la Cueva de Pedro Fernández los materiales nos indican que, además de función funeraria, la cueva fue ocupada como lugar de habita- 
ción (Sánchez Meseguer, 1979: 119), y en la de Juan Barbero parece que el poblado se localizó en el mismo cerro, en las inmediaciones de la cueva (Martínez-Navarrete, 1984: 18). Esta asociación parece ser la característica más llamativa para ambos modelos de enterramiento, cuya excepción podría ser la cueva de El Rebollosillo, aunque no debemos olvidar que se trata de un hallazgo casual y que no se han realizado prospecciones en los alrededores que descarten la existencia de un lugar de habitación.

Tanto el empleo de cuevas y covachas naturales como lugares de enterramiento como la excavación de fosas entre estructuras habitacionales o de almacenaje son tradiciones de probable raigambre neolítica. En el caso de las cuevas, no tenemos ningún dato que confirme de forma evidente que se trate de un rito extendido en la región durante el Neolítico, si bien los datos de las regiones circundantes impiden descartar esta posibilidad (Blasco, 1997: 173) y, de hecho, la convierten en bastante probable. En el caso de las fosas de enterramiento dentro de área de habitación, el Arenero de Valdivia (Jiménez Guijarro, 2001) es el mejor ejemplo de que estas prácticas se producen en Madrid desde el Neolítico Inicial.

Las diferencias entre ambas formas de inhumación son evidentes en lo referente a la estructura de enterramiento, y aún son más acusadas en lo referente al rito. En las cuevas encontramos siempre enterramientos colectivos no-sincrónicos, resultado de la acumulación de sucesivas deposiciones funerarias, y en ningún caso enterramientos múltiples simultáneos, hecho que viene corroborado por la presencia de huesos en posición secundaria, desplazados de su lugar y amontonados formando paquetes, como se documentan en El Rebollosillo (Díaz-Del-Río, 1996: 198) y en La Cueva de Juan Barbero (Bermúdez de Castro y Pérez, 1984: 113-117). Es muy probable que la presencia de estos enterramientos desplazados respondan a una reordenación del espacio funerario llevada a cabo con motivo de la realización de nuevas inhumaciones en el interior de la cueva, lo que explicaría, quizás, la presencia de huesos quemados (El Rebollosillo, Juan Barbero), que nos hablarían del empleo del fuego como forma de purificar y limpiar el lugar de enterramiento (Martínez Navarrete, 1984: 35; Fabián García, 1995: 134). El hecho de que se emplee un mismo espacio funerario para enterrar en él a varios miembros de la comunidad nos podría estar hablando de verdaderos panteones parentelares o comunales, lo que en cierto modo podría explicar su uso continuado a lo largo del tiempo: la conciencia de pertenencia al grupo, ya sea éste de parentesco o más amplio, llevaría a sus miembros a elegir un lugar común para enterrarse durante su periodo de permanencia en ese lugar, que podría ser muy dilatado en el tiempo, explicando la presencia de materiales de épocas posteriores. Pero también es posible que la elección del lugar estuviese condicionada por concepciones religiosas o simbólicas que no conocemos, y que fuese este valor el que determinase el empleo de las cuevas como lugares de enterramiento. De esta manera, diferentes grupos podrían enterrarse en un mismo lugar motivados por la significación simbólica que éste tendría para su mundo religioso y funerario, sin que en ello interviniesen lazos de parentesco (Fabián García, 1995: 127-128).

Los enterramientos en fosa documentados hasta la fecha, en cambio, no parecen responder a las mismas motivaciones, ya que es frecuente encontrar varias de estas sepulturas en un mismo yacimiento, y éstas no presentan enterramientos formados por la deposición sucesiva de un número significativo de individuos. Para Fabián García el enterramiento en fosa dentro o cerca del área de habitación carecería de significación religiosa y sería consecuencia del resultado del empleo de un mismo lugar como sepultura para los miembros de la comunidad que fallecieron durante el periodo de tiempo en el que ocuparon el poblado, no demasiado largo, sin que en ello mediasen sentimientos de colectividad, sino simplemente aspectos funcionales (Fabián García, 1995: 126-127). Sin embargo, esta idea parte del presupuesto de que las fosas halladas en un mismo yacimiento no son contemporáneas, algo que desconocemos y no podemos descartar, y que la ocupación de estos lugares es estacional y breve, lo que no parece corresponderse con los datos que aportan las investigaciones más recientes. Una posibilidad es que fuese la necesidad de mantener un espacio común o adyacente entre los vivos y los muertos lo que impulsase a ciertas comunidades, asentadas en parajes en llano donde no existen cuevas o covachas cercanas, a continuar realizando enterramientos en fosa dentro de los poblados como habían hecho durante el Neolítico, aunque esto no explicaría la coexistencia de enterramientos de tipo colectivo, realizados en cueva, con enterramientos de carácter individual, al aire libre. 
Un caso especial lo constituye el enterramiento en fosa de varios individuos, que podemos denominar múltiple, y que se ha documentado por primera vez en esta región a partir de las excavaciones realizadas en Camino de las Yeseras, caracterizado por la inhumación simultánea o en un breve espacio de tiempo de varios individuos, entre 4 y 8 (Liesau et al., 2008: 109-111; Blasco et al., en prensa).

Se trata de inhumaciones primarias, puesto que mantienen la mayor parte de las conexiones anatómicas y en las tumbas se encuentran presentes huesos de muy pequeño tamaño (falanges distales, e incluso sesamoideos) que nos indican que los cuerpos fueron depositados allí antes de que hubiese tenido lugar su esqueletización. Además, la relación espacial entre los individuos enterrados en las fosas nos induce a pensar que se trata de deposiciones sincrónicas, ya que los restos esqueléticos de unos y otros se superponen en directo contacto y guardando la conexión, y no existe ningún tipo de alteración del cierre de las tumbas y del depósito sedimentario que colmató los enterramientos que nos indique la existencia de posteriores aperturas con la finalidad de introducir nuevos cuerpos.

Los paralelos más cercanos a este tipo de enterramientos hay que buscarlos en el valle del Ebro (Andrés Rupérez, 1989-1990) o en Ávila (Fabián García, 2006: 307-311), y su existencia complica aún más el panorama de las prácticas funerarias calcolíticas de la Región de Madrid, donde hemos visto que coexisten, al menos, con dos formas más de enterramiento no-campaniforme: enterramiento en cueva de carácter colectivo y enterramiento en fosa simple individual.

El análisis de los ajuares de los enterramientos no-campaniformes no resuelve el problema que plantea la aparente coexistencia de diferentes formas funerarias, ya que no existen diferencias suficientes en su composición como para hacernos pensar que la elección del rito y la tumba responda a diferencias de estatus entre los enterrados. Parece constatarse un predominio de ofrendas cerámicas, dentro de las cuales son mayoritarios los cuencos hemiesféricos, documentados en El Rebollosillo (Díaz-Del-Río, 1996: 199), Pedro Fernández (Sánchez Meseguer, 1979: 120), Juan Barbero (Martínez-Navarrete, 1984: 55), Camino de las Yeseras (Blasco et al., en prensa) y Valdocarros, aunque en este último yacimiento no conocemos si se asociaban a los enterramientos.
Sólo en tres casos tenemos documentados elementos que podemos considerar adornos o amuletos, como son las cuentas de collar fabricadas en piedra de Camino de las Yeseras, El Rebollosillo y Pedro Fernández, que entroncan directamente con la tradición neolítica (Díaz-Del-Río, 1996: 199; Blasco, 1997: 174), y los colgantes de colmillos del jabalí de esta misma cueva (MartínezNavarrete, 1987: 71). Son ajuares muy homogéneos, donde apenas podemos percibir diferencias de composición que nos indiquen distinciones sociales o de rango, y donde no aparecen objetos de metal.

El tratamiento de los restos humanos es, sin duda, uno de los aspectos más interesantes dentro de estas prácticas funerarias no-campaniformes, sobre todo en el caso de los enterramientos colectivos. Todo parece indicar que el grado de desconexión anatómica en la que se encuentran muchos de los cuerpos responde a dos motivos, uno de origen natural (remociones de tierras como en el caso de la cueva de Juan Barbero) y otro de origen antrópico (El Rebollosillo), motivado por la necesidad de reordenar el espacio de inhumación colectiva con la finalidad de introducir nuevas inhumaciones, como ocurre en otras zonas de la península, tanto en cuevas como en megalitos.

Existen, además, otros indicios de prácticas rituales relacionadas con el tratamiento de los restos humanos como el uso del fuego o de pigmentos. El primero de los casos se documenta tanto en la cueva de El Rebollosillo como la de Juan Barbero, además de en uno de los enterramientos en fosa múltiple de Camino de las Yeseras, y el segundo se ha constatado en Juan Barbero, Camino de las Yeseras y La Salmedina. En estos tres yacimientos se han documentado restos humanos cubiertos parcialmente con colorante rojo, una práctica que parece estar bastante extendida en la Península Ibérica desde época Neolítica (Rubio de Miguel, 2001-2002: 54; MartínezNavarrete, 1984: 34), pero de la cual desconocemos su posible significado.

Otra novedad ofrecida por Camino de las Yeseras con respecto al tratamiento de los cuerpos es la que han proporcionado dos enterramientos singulares de este yacimiento, caracterizados por la presencia de restos humanos parciales, que en al menos una ocasión, nos permiten hablar del desmembramiento o descuartización del cuerpo del inhumado, sin que podamos saber si esta práctica fue realizada perimortem o postmortem. Es lo 
que se deduce de uno de los enterramientos, donde parece claro que se ha enterrado "medio" individuo adulto, ya que encontramos en perfecta conexión anatómica el sacro, los coxales y las extremidades inferiores con sus pies, pero ningún elemento óseo perteneciente al tronco superior del sujeto (Blasco et al., en prensa).

\section{Los enterramientos campaniformes.}

Los conjuntos funerarios campaniformes documentados hasta ahora son más numerosos (Arenero de Soto, Arenero de Miguel Ruiz, Barranco del Conejero, Cerro del Tomillo, La Aldehuela, Las Carolinas, Juan Francisco Sánchez, Ciempozuelos, La Salmedina, Mejorada del Campo, Caserío de Perales del Río, Camino de las Yeseras y el dolmen de Entretérminos), y, en la Región de Madrid, parecen presentar una menor variabilidad con respecto a las prácticas descritas anteriormente.

A excepción del megalito de Entretérminos, el resto de ejemplos son tumbas excavadas en el suelo, con una morfología bastante diversa, que va desde la simple fosa hasta la cueva artificial, de la que tendríamos ejemplos en Ciempozuelos (Riaño et al., 1894: 436) y en Camino de las Yeseras. Esta escasa representación de enterramientos campaniformes vinculados a megalitos contrasta con lo que sucede en el resto de la Meseta, donde se documenta una veintena de casos de asociación entre estos monumentos y ajuares campaniformes, aunque en la mayoría se encuentran descontextualizados y resulta difícil relacionarlos con los restos humanos. El número de megalitos en la Meseta con presencia de material campaniforme es, por tanto, algo superior al de las tumbas campaniformes no-megalíticas (Garrido et al., 2005: 415), al revés de lo que sucede en la región madrileña. A estos datos de la Meseta habría que sumar la existencia de una decena de cuevas de enterramiento colectivo en las que han aparecido materiales campaniformes entremezclados con restos humanos (Garrido et al., 2005: 417), de las que no tenemos ningún ejemplo en la región de Madrid.

En nuestra región, hasta el hallazgo de dos hipogeos y cinco "covachas" artificiales en Camino de las Yeseras, las tumbas excavadas en el suelo con ajuar campaniforme se diferenciaban únicamente de las no-campaniformes en la presencia de este tipo cerámico entre los elementos de ajuar, si bien es cierto que en la mayoría de los casos las fosas con esta cerámica presentan cubriciones o cierres realizados con piedras, que en ocasiones permiten hablar de pequeños túmulos (Arenero de Soto, Juan Francisco Sánchez, La Salmedina y Perales del Río), e incluso lajas-estela (Arenero de Miguel Ruiz). Es muy probable que este tipo de estructuras sirviesen como elementos de señalización del lugar de enterramiento (Blasco, 1997: 174 y 1998: 150), además de facilitar el cierre de las tumbas, que presentan una planta de tendencia oval o rectangular, con unos ejes de algo más de un metro y medio por un metro y escasa profundidad (Blasco, 1997: 174; Garrido et al., 2005: 414). Al margen de esta diferencia, al igual que las no-campaniformes, estas fosas se encuentran en relación espacial directa con las zonas de habitación (Blasco, 1997: 175), ya sea por proximidad relativa (Ciempozuelos, $\mathrm{La}$ Aldehuela), o por ubicarse junto a las estructuras de hábitat (Perales del Río, Arenero de Soto).

Este panorama ha variado sustancialmente, como ya he mencionado, con los hallazgos producidos en Camino de las Yeseras, donde la diferencia entre las tumbas excavadas en el suelo con y sin campaniforme no estriba únicamente en la incorporación de vajilla campaniforme a los ajuares, sino también en una serie de rasgos característicos que los diferencian del resto de enterramientos y que afectan a la estructura arquitectónica de las tumbas, mucho más compleja: las tumbas con ajuares campaniformes responden a la morfología de cuevas artificiales, covachas o hipogeos, y forman parte de estructuras arquitectónicas de mayores dimensiones semejantes a cabañas (Liesau et al., 2008: 111-116) (Figura 1).

En cualquier caso, con los datos de los que disponemos, parece constatarse que el ritual funerario característico campaniforme para la región madrileña es el enterramiento en estructura excavada en el suelo, mayoritariamente fosa simple, de un único individuo, aunque no faltan ejemplos de enterramientos dobles, triples, o de más cuerpos, formados como consecuencia de enterramientos sucesivos no sincrónicos (Juan Francisco Sánchez, La Salmedina, Camino de las Yeseras). Hay que destacar que en todos los casos de deposiciones primarias con ajuares campaniformes los cuerpos de los inhumados se disponen en posición fetal o contraída, posición que es también única para el resto de ejemplos de la meseta (Garrido, et al. 2005: 419), acostados tanto del lado derecho 


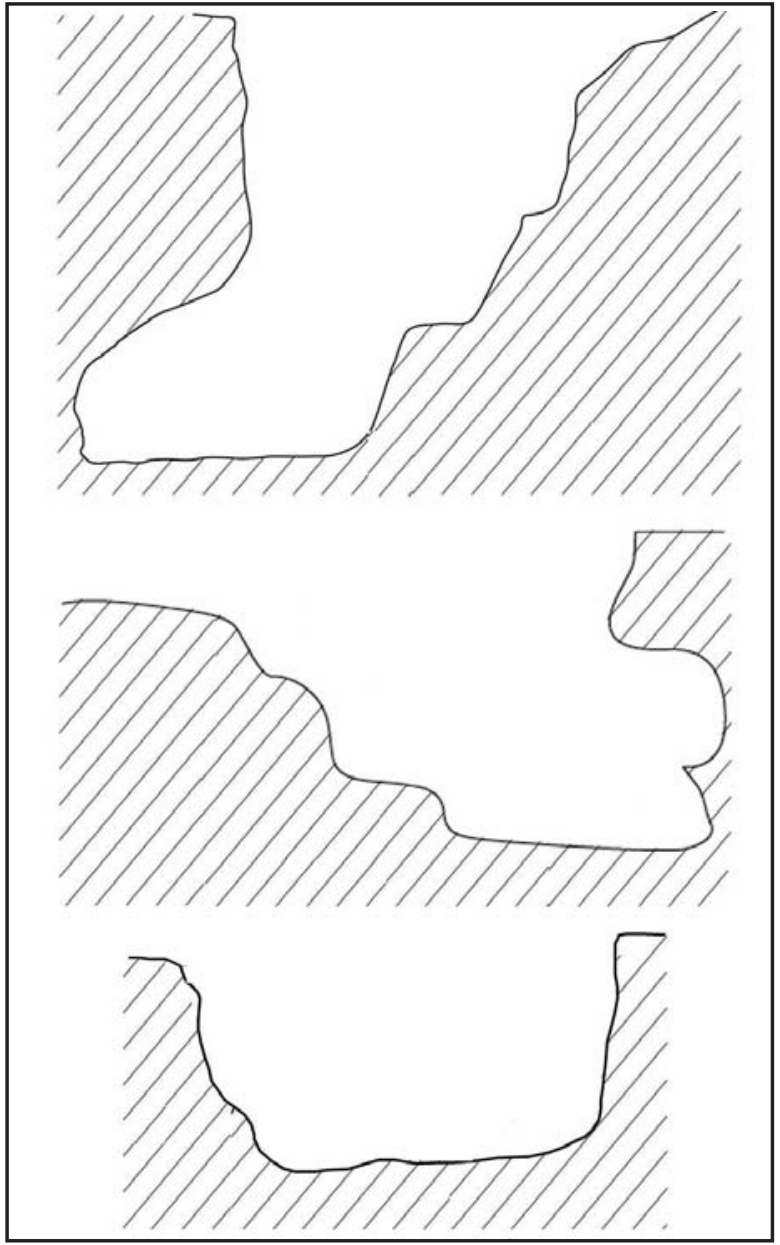

Fig 1.- Sección de un hipogeo (arriba), una covacha (en medio) y una fosa simple (abajo) de Camino de las Yeseras (dibujos ARGEA S. L.).

como del izquierdo y sin una orientación fija, con los brazos cruzados o replegados junto al cuerpo y las manos a la altura del pecho o del abdomen. Por el contrario, los cuerpos de los enterramientos no-campaniformes en fosa presentan una mayor variabilidad de posturas, más acusada en el caso de los enterramientos múltiples, donde se observan cuerpos en posiciones muy forzadas.

A pesar de contar solamente con un ejemplo de enterramiento campaniforme en megalito, debemos plantearnos el porqué de la convivencia de éste tipo de sepultura con los enterramientos en fosa. Un elemento importante a tener en cuenta es la dicotomía geográfica existente entre el emplazamiento de estos dos tipos de sepultura, ya que frente a la ubicación serrana de Entretérminos, la totalidad de enterramiento en fosa campaniformes se localizan en los tramos medios y bajos de las cuencas fluviales. Es muy posible que estas diferencias estén en relación, por tanto, con formas de ocupación y poblamiento diferentes (Díaz-delRío, 2001: 28-29), y en este sentido, algunos autores han apuntado la posibilidad de que fuese la inexistencia de las materias primas necesarias para la construcción de monumentos megalíticos en las cuencas fluviales las que condicionasen el tipo de sepultura desarrollado en las mismas, en cuyo caso el túmulo de piedras sería la única forma de señalización viable para estos paisajes (Blasco et al., 1994: 96). En cualquier caso, el uso de megalitos para albergar sepulturas campaniformes se produce de forma habitual en otras zonas de la Meseta, y en la mayoría de ocasiones se trata de reutilizaciones de monumentos más antiguos lo que, en opinión de Garrido no responde a una continuidad ideológica e implica una forma diferente de concebir el rito funerario (Garrido, 2000: 55-57). Prueba de ello sería la existencia de remodelaciones arquitectónicas y enterramientos individuales dentro de estos monumentos, tradicionalmente empleados como lugares de enterramiento colectivo, si bien en el caso de Madrid no tenemos ninguna constancia del uso de Entretérminos con estos fines en momentos precedentes. No obstante, el hecho de que el enterramiento campaniforme documentado en este megalito se hallase en el corredor, y no en la cámara, podría indicar que su construcción y primera utilización responden a un momento precedente (Losada, 1976: 211).

Los ajuares de las sepulturas campaniformes se componen, fundamentalmente, de objetos cerámicos, lisos y decorados, junto a los que aparecen objetos metálicos (punzones, puñales, puntas de Palmela), de adorno (diademas, brazaletes, cuentas de collar, botones), brazales de arquero, molinos y morteros, etc. Al contrario de lo que ocurre en los casos no-campaniformes los ajuares sí que presentan importantes diferencias en su composición, de tal manera que encontramos ajuares muy ricos, con presencia de lotes cerámicos campaniformes, armas de metal, e, incluso, orfebrería (Arenero de Miguel Ruiz, Entretérminos), ajuares que, si bien no alcanzan el nivel de los anteriores, mantienen un grado de riqueza importante, evidenciado en el número de vasos y la presencia de metal (Ciempozuelos, La Salmedina o los conjuntos de Mejorada del Campo), y ajuares muy modestos, compuestos únicamente por cerámica (Perales del Río, Arenero de Soto o Juan Francisco Sánchez). El hecho de que existan ajuares de composición tan distinta puede explicarse por la aparición de las primeras diferencias socia- 
les de rango o estatus dentro de la comunidad, aunque también podría deberse al diferente grado de acceso a las fuentes de metal que unos grupos $\mathrm{u}$ otros podrían tener y a distintas tradiciones locales (Blasco et al., 1994: 98). Un dato a destacar es que en aquellos casos en los que se han documentado los ajuares in situ, los recipientes cerámicos campaniformes se encuentran en lugares muy próximos al cuerpo del inhumado, a la altura de la cabeza, del abdomen o de los pies, de manera que podríamos hablar de una clara individualización de las ofrendas e incluso, de una relación de propiedad por parte del inhumado con respecto a las mismas.

\section{EXPLICACIÓN A LA DIVERSIDAD DE PRÁCTI- CAS FUNERARIAS DEL CALCOLÍtico EN LA REgIÓN DE MADRID}

La variedad de formas de enterramiento existentes presenta, a simple vista, una difícil interpretación, sobre todo por la ausencia de criterios de clasificación cronológica válidos basados en dataciones y no en la ausencia de cerámica campaniforme como indicador de antigüedad. Esto impedía establecer una secuencia diacrónica de las prácticas funerarias calcolíticas, de modo que hasta hace muy poco éramos totalmente incapaces de establecer si realmente los diferentes tipos y modos de enterramiento que se constatan en la región para el Calcolítico eran o no sincrónicos.

Sin embargo, el panorama ha cambiado gracias a las dataciones relativas a conjuntos funera- rios que ha proporcionado Camino de las Yeseras, que corroboran la escasa validez de los criterios de discriminación tipológica como método de ordenación cronocultural. Así, ciertas fechas de enterramientos no-campaniformes de este yacimiento coinciden con algunas de las obtenidas de conjuntos campaniformes halladas en el mismo, indicándonos una convivencia entre ritos y ajuares funerarios claramente distintos, dentro de una misma sociedad y de un mismo yacimiento, que por otro lado refleja una importante continuidad a lo largo de todo el III milenio a. C.

Con las fechas proporcionadas por los enterramientos de este yacimiento podemos inferir que los enterramientos con y sin campaniforme surgen de manera casi simultánea, en torno al 2400 a. C., en la segunda mitad del III milenio a. C., y que ambas formas continúan a lo largo de casi mil años. En líneas generales, percibimos una mayor modernidad para los enterramientos con campaniforme frente a los no-campaniformes, que son, generalmente, más antiguos; sin embargo, las dataciones obtenidas permiten hablar de un claro periodo de convivencia entre ambas formas dentro de este yacimiento (Figura 2).

Los datos radiocarbónicos con los que contamos son aún muy escasos, y se limitan a este único yacimiento, pero si se confirmasen con nuevas dataciones y hallazgos podríamos considerar que tanto los enterramientos no-campaniformes como los campaniformes realizados en fosa al aire libre son, en líneas generales, propios de un

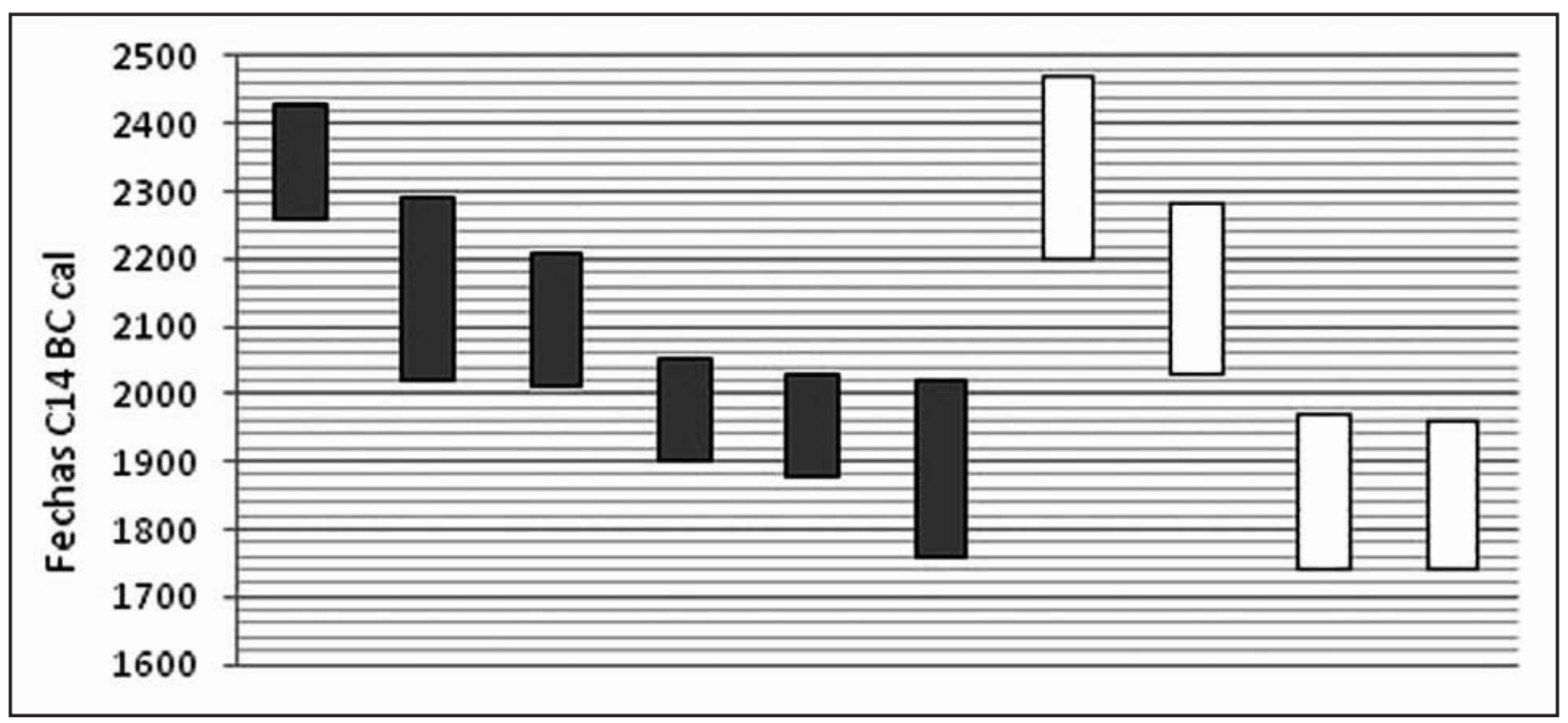

Fig 1.- Tabla con las dataciones obtenidas de los enterramientos de Camino de las Yeseras. En gris las fechas referidas a conjuntos sin cerámica campaniforme y en blanco los conjuntos con campaniforme. 
momento avanzado dentro del III milenio a. C.. En ese caso, sólo nos quedaría establecer si la forma característica de dar sepultura a los muertos para la primera mitad del Calcolítico es la inhumación colectiva en cueva, como ha sostenido Díaz-del-Río, según el cual se observaría una tendencia diacrónica clara en las pautas de enterramiento calcolíticas de la región madrileña, consistente en el paso del enterramiento colectivo en cueva o espacio natural al enterramiento individual en fosa dentro de poblado (Díaz-del-Río, 2001: 162).

Como siempre, nos encontramos ante la ausencia de dataciones que permitan establecer unos límites temporales claros para este tipo de enterramientos, aunque contamos con el paralelo de Jarama II, situado en la provincia de Guadalajara, muy cerca de la frontera de ésta con Madrid, que ha proporcionado una fecha calibrada de 2891-2622 a. C. (Jordá y Mestres, 1999), lo que sitúa esta inhumación colectiva en cueva en un momento inicial del Calcolítico. Tomando como referente las fechas de Jarama II y la posibilidad de que fuesen extrapolables a los enterramientos de El Rebollosillo, Juan Barbero o Pedro Fernández, y el hecho de que se trata de una forma funeraria documentada también en el Neolítico Final, de la que quizás pudiese ser ejemplo la Cueva del Aire, en Patones, podríamos establecer este tipo de manifestación funeraria como la forma de enterramiento característica de las primeras etapas del Calcolítico. Más aún si comparamos esta fecha con la más antigua disponible para el resto de formas no-campaniformes, proporcionada por uno de los enterramientos de Camino de las Yeseras (2620-2430 BC cal), con la que se aprecia un perfecta diacronía.

De corroborarse esta hipótesis de secuenciación con los resultados de nuevas dataciones, podríamos establecer una periodización para el Calcolítico de la región de Madrid a partir de la tipología de las prácticas funerarias, estableciendo, al menos, dos momentos diferentes:

- Calcolítico Inicial, mal definido aún, pero que podría caracterizarse por el enterramiento colectivo en cueva (y quizás en megalito), y que ocuparía la primera mitad del III milenio a. C., y seguramente los últimos siglos del IV, entroncando con la tradición del Neolítico Final (3000-2500 aprox.); y
- Calcolítico Pleno, caracterizado por el enterramiento en fosa dentro o cerca de poblado, predominantemente individual, con y sin cerámica campaniforme entre los elementos de ajuar, que se desarrollaría en la segunda mitad del III milenio a. C. y los primeros siglos del II (2500-1800 a. C. aprox.).

A la luz de estos datos podemos matizar la periodización establecida por Díaz-del-Río para Madrid, que señala un Calcolítico Precampaniforme entre el 3050 y el 2200 a. C. y un Calcolítico Campaniforme entre el 2750 y el 1500 a. C. (Díaz-del-Río, 2001: 69), y explicar esos 500 años de solapamiento entre una fase y otra por a la existencia de contextos arqueológicos sin campaniforme en una etapa en la que ya ha hecho acto de presencia este tipo de cerámica.

Teniendo en cuenta los nuevos datos y la hipótesis de periodización propuesta a partir de los mismos, podemos clasificar y ordenar tipológicamente las prácticas funerarias calcolíticas de la región de Madrid de la siguiente manera:

\section{- CALCOLÍTICO INICIAL:}

- Enterramientos colectivos en cueva (El Rebollosillo, Cueva de Pedro Fernández y Cueva de Juan Barbero).

\section{- CAlCOLÍtico PLENo:}

Enterramientos no-campaniformes:

- Enterramientos múltiples en fosa dentro de poblado (Camino de las Yeseras).

- Enterramientos individuales en fosa dentro de poblado (Las Fronteras, y Camino de las Yeseras).

- Enterramientos dobles en fosa dentro de poblado (Valdocarros y Camino de las Yeseras).

- Enterramientos parciales en hoyo o fosa dentro de poblado (Camino de las Yeseras).

Enterramientos campaniformes:

- Enterramientos en fosa al aire libre (Arenero de Miguel Ruiz, Barranco Conejero, Catedral Santa María Magdalena, Cerro del Tomillo, Ciempozuelos, Mejorada del Campo I y II, y Perales del Río).

- Enterramientos en fosa dentro de poblado (Arenero de Soto, Camino de las Yeseras, Juan Francisco Sánchez, La Salmedina y Las Carolinas). 
- Enterramientos dentro de monumentos megalíticos (Entretérminos).

- Enterramientos en cueva artificial: covacha o hipogeo (Camino de las Yeseras y Ciempozuelos).

Esta clasificación basada en criterios cronológicos ofrece la posibilidad de analizar las formas funerarias conocidas para esta región con el fin de interpretarlas en clave histórica, es decir, dentro del contexto socio-económico y cultural en el que se desarrollan para entender los cambios acontecidos en las prácticas funerarias a lo largo del Calcolítico.

\section{Los enterramientos del Calcolítico Inicial.}

Las características definitorias de este tipo de tumbas son la elección como contenedor de una arquitectura en roca de dimensiones importantes, que en el caso de las cuevas, además, es natural, y la práctica de la inhumación colectiva no-simultánea, aspectos que lo diferencian del resto de formas de enterramiento calcolíticas.

El rito de inhumación colectiva no-simultánea queda reflejado en estas tumbas en la existencia de paquetes óseos o enterramientos desplazados dentro de la sepultura que a veces conviven con cuerpos en posición primaria o restos en diferente grado de conexión anatómica. Este tipo de inhumación, que denominamos colectiva, podría considerase como la manifestación funeraria propia de una sociedad en la que existen fuertes lazos entre los individuos que conforman un grupo o comunidad, ya sean éstos de carácter familiar, clánico-tribal o político-social. Este sentimiento de pertenencia a un colectivo se acentúa si tenemos en consideración el hecho de que en la mayor parte de los casos estas sepulturas están en las inmediaciones de lugares de hábitat, relación espacial que implica la existencia de un vínculo entre el mundo de los vivos y el de los muertos, relación, no obstante, que se mantendrá en momentos posteriores, no sólo dentro del Calcolítico, sino también durante la Edad del Bronce.

El tratamiento de los restos humanos que conlleva este tipo de tumbas es común a Europa Occidental durante el III milenio a. C., y algunos investigadores la han interpretado como una fórmula de "desenfatizar la individualidad" de los inhumados dentro de sociedades igualitarias de carácter colectivista (De Marrais et al., 1996: 21). Estas sociedades tendrían una organización de tipo clánico-tribal, donde los lazos de parentesco serían la base sobre la que se asienta la identidad social del sujeto dentro de su comunidad. Para Díaz-del-Río, en cambio, el hecho de que parte de los restos óseos guarden las conexiones anatómicas indica un deseo de identificar a cada individuo, por lo que opina que en el Calcolítico "el tratamiento de los huesos es en gran medida individualizado" (Díaz-del-Río, 2001: 292).

En cualquier caso, la práctica de enterrar en un mismo lugar a un conjunto de individuos de forma diacrónica en el tiempo no parece que sea producto del azar o de las circunstancias, y mucho menos resultado de la practicidad, como a veces se ha sostenido (Fabián García, 1995: 126), sino que debemos considerarla una práctica funeraria específica de un momento prehistórico concreto y resultado de unas circunstancias sociales determinadas.

Como sostuvo Criado Boado, el fenómeno megalítico puede considerarse una forma de reivindicación del territorio por parte de una comunidad mediante la apelación a la tradición y a sus muertos (Criado Boado, 1989), y podríamos incluir en esta afirmación las cuevas de inhumación colectiva, más aún si, como señala Díaz-delRío, el origen de las sociedades plenamente campesinas y del paisaje agrario se produce en los primeros siglos del III milenio a. C., momento en el que parecen desarrollarse este tipo de prácticas funerarias. De este modo, podríamos considerar que el enterramiento colectivo en cueva (y en megalito) es una forma de demarcación territorial y de legitimación de los derechos de explotación de los recursos por parte de las comunidades que ocupaban esos territorios.

\section{Los enterramientos del Calcolítico Pleno.}

A medida que avanza el Calcolítico, va consolidándose un modo de vida basado en un modelo de economía campesina, que se refleja en la proliferación de los asentamientos denominados "de hoyos" y en los resultados de los análisis paleobotánicos y faunísticos (Díaz-del-Río, 2001: 310). Las primeras comunidades calcolíticas de la región habrían sufrido durante este tiempo una serie de transformaciones y cambios históricos que en el panorama de las prácticas funerarias se reflejaría en el paulatino abandono del enterra- 
miento colectivo en cueva o megalito y en la adopción de un modelo basado en la inhumación individual en fosas dentro de las mismas áreas donde se localizan los lugares de hábitat.

Siguiendo la clasificación mencionada, el primer tipo de enterramiento no-campaniforme de este tipo es el enterramiento múltiple en fosa.

Para autores como Fabián (1995: 125-127), este tipo de enterramientos son paralelos a los enterramientos colectivos en cueva o megalito, partiendo de la base de que se trata de inhumaciones múltiples no-simultáneas. Sin embargo, para el caso madrileño no está tan claro que nos encontremos ante fenómenos de este tipo, ya que, casi con total seguridad, la mayor parte de estos enterramientos responden a inhumaciones múltiples sincrónicas en el tiempo.

Teresa Andrés Rupérez señala la excepcionalidad que supone la inhumación múltiple simultánea en el Calcolítico, que responde a la idea de fosa común y no deriva de parámetros culturales, religiosos o cultuales, sino que es fruto de la necesidad y, por tanto, es una anomalía dentro del registro funerario (Andrés Rupérez, 1989-1999: 15). Menciona, además, ejemplos como los de la Atalayuela de Agoncillo, en la Rioja, o La Venta del Griso, en Valderrobes, en los que se han hallado puntas de flecha, que podrían evidenciar que los inhumados en estos sepulcros fueron víctimas de una acción bélica o de un enfrentamiento, casos que también se documentan en la región de Madrid, donde contamos con un enterramiento de Camino de las Yeseras que albergaba los restos de siete individuos junto con siete puntas de flecha, muchas de ellas fracturadas y con posibles marcas de impacto. Existen, por tanto, indicios que permiten pensar que estamos ante el depósito funerario de individuos muertos por causas no-naturales, seguramente derivadas de un conflicto armado, a pesar de que las edades de los inhumados (entre 1 y 35 años, siendo mayoritariamente niños) impide pensar en grupo de guerreros abatidos en combate.

Un paralelo para este enterramiento es el Enterramiento 1 del Cerro de la Cabeza, en el Valle del Amblés, en Ávila, donde se hallaron los restos de seis individuos "inhumados de forma simultánea en una fosa ligeramente ovalada de 1,83 por 2,05m" (Fabián García, 2006: 307). En este caso se trata de individuos adultos y jóvenes, con edades comprendidas entre los 15 y los 35 años, entre los que se encontraban cinco hombres y una mujer, dispuestos en diversas posturas, algunas de ellas algo forzadas, "adaptados a las dimensiones de la fosa" (Fabián García, 2006: 307), como sucede también en el caso de los enterramientos múltiples de Camino de las Yeseras. Lo más destacado de este enterramiento es que se hallaron cuatro puntas de flecha, algunas de ellas aún clavadas en los huesos de algunos de los individuos (individuo 2, 3, 5 y 6), que indican que sin duda al menos cuatro de los inhumados fallecieron de muerte violenta, y es muy posible, como señala Fabián García, que los dos restantes murieran de la misma forma (Fabián García, 2006: 311). Las dataciones radiocarbónicas de este enterramiento dan una fecha de 2580-2300 a. C., coincidiendo con la etapa de presencia de cerámica campaniforme en la Meseta Norte a pesar de que no se ha hallado ningún fragmento de campaniforme en esta inhumación, cronología que barajamos también para los enterramientos de este tipo en la región de Madrid, a juzgar por las fechas obtenidas de Camino de las Yeseras (2620-2430 a. C.).

El siguiente tipo de enterramiento no-campaniforme del Calcolítico de la región de Madrid es la inhumación individual en fosa dentro de poblado, de la que contamos con varios ejemplos, pertenecientes en su mayor parte a Camino de las Yeseras (San Fernando de Henares).

Tradicionalmente, el enterramiento individual se consideraba privativo del fenómeno campaniforme, pero los datos proporcionados por Camino de las Yeseras permiten constatar que se trata de una forma funeraria con bastante representatividad, constituyendo en este yacimiento la más común entre los enterramientos no-campaniformes. Si tenemos en cuenta el carácter especial que presentan el resto de formas y la abundancia de este tipo de enterramientos, a los que hay que sumar las inhumaciones individuales campaniformes, podemos decir, casi con total seguridad, que la práctica funeraria característica para el Calcolítico Pleno es el enterramiento individual. Éste, en el caso de los no-campaniformes, se realiza en fosas de tendencia circular u oval y de tamaño diverso, excavadas en el suelo cercano a estructuras de habitación o almacenaje $\mathrm{y}$, por tanto, dentro del área del poblado.

En ninguno de los casos documentados se han localizado elementos de ajuar perteneciente a los individuos allí inhumados, que están colocados en posición de decúbito lateral, con las piernas fle- 
xionadas, lo que, por otro lado, no constituye una práctica funeraria privativa de la región madrileña, como demuestran los ejemplos de Las Cañamonas, en San Cristóbal de Entreviñas (Zamora), o de Ciguñuela (Valladolid), en los que tampoco se han constatado ajuares (Fabián García, 1995: 110-111 y 115).

El siguiente tipo de enterramiento no-campaniforme es el enterramiento doble en fosa, del que tenemos una datación procedente de Camino de las Yeseras que corrobora su contemporaneidad con el resto de manifestaciones funerarias nocampaniformes (2130-2080 BC cal). Dentro de este tipo debemos establecer, no obstante, una distinción entre aquel que es resultado de la inhumación simultánea de los fallecidos (a) y el que es consecuencia de la deposición de un segundo cadáver en una tumba ocupada ya por un individuo (b). Se trata de un tipo de enterramiento muy minoritario en la muestra de enterramientos nocampaniformes, aunque no tan excepcional si tenemos en cuenta también las tumbas campaniformes.

Del primer tipo de enterramiento doble (a) tenemos sólo dos ejemplos para el área madrileña, en Camino de las Yeseras y en Valdocarros, si bien existen algunos ejemplos fuera de nuestro ámbito regional, como el enterramiento de El Ollar, en Donhierro (Segovia) (Delibes de Castro, 1988). Las fosas que albergan a estos inhumados no son diferentes a las otras documentadas para el resto de enterramientos no-campaniformes, y apenas difieren de los hoyos de diferente funcionalidad que constituyen, junto a las cabañas, los poblados calcolíticos de la región central de la península.

Las razones para explicar el fenómeno de la inhumación doble, frente a la individual o a la múltiple, pueden ser muy variadas, más aún si tenemos en cuenta la escasez de ejemplos y la parquedad de los datos obtenidos de los existentes. No obstante, el hecho de que se trate de inhumaciones simultáneas las asemeja más a los enterramientos múltiples, y es más que probable que en ambos casos estemos ante sepulturas de carácter excepcional condicionadas por una muerte sucedida en circunstancias anómalas. El número de inhumados podría no ser definitorio de un tipo concreto de enterramiento, sino consecuencia del número de "víctimas" mortales resultante de unas circunstancias especiales, y, por tanto, estaría al margen de la intencionalidad del grupo que dio sepultura a los cuerpos. No obstante, hay que tener en cuenta un hecho importante, y es que tanto en Camino de las Yeseras como en Valdocarros los inhumados en estos enterramientos responden a parejas formadas por un hombre y una mujer, factor que podría ser indicativo de la existencia de vínculos matrimoniales entre los fallecidos que explicasen la intencionalidad de dar sepultura conjunta a los cadáveres. El número de ejemplos es aún muy escaso, pero de confirmarse esta pauta habría que considerar que los enterramientos dobles simultáneos, aunque fruto de circunstancias de muerte anómalas, responden a una pauta normalizada y no al simple azar.

Frente a este tipo de enterramiento doble, hemos mencionado la existencia de otro (b), caracterizado por la inhumación de los restos de dos individuos en un mismo sepulcro de manera no-simultánea. Es el caso de otro de los enterramientos de Valdocarros, resultado de la inhumación de dos individuos fallecidos en momentos muy distintos. Se trata de un tipo de rito funerario que implica la manipulación de los cuerpos, de forma semejante a lo que ocurre en las tumbas colectivas, aunque no tenemos datos suficientes para saber si se trata de un enterramiento primario al que se le ha añadido uno secundario (los restos de dicho individuo han sido trasladados desde otra ubicación ya en estado esquelético) o si es el resultado del desplazamiento de los restos de un primer enterramiento con la finalidad de hacer hueco para la deposición de un segundo cadáver. Se trata de un fenómeno que también documentamos en los enterramientos campaniformes, donde son más abundantes los casos de enterramientos dobles (e incluso múltiples) resultado de inhumaciones donde los cadáveres no se han enterrado de forma simultánea.

El último tipo de manifestación funeraria nocampaniforme, por sus características y su escasez, resulta muy difícil de explicar. Se trata de lo que hemos denominado "enterramientos parciales en hoyo o fosa dentro de poblado", que se caracterizan por la parcialidad del/de los esqueleto/s que componen el registro, parcialidad que no se explica por procesos posdeposicionales sino por la acción antrópica.

No conocemos la explicación para este desmembramiento, ni sabemos si éste se produjo ante-mortem (en cuyo caso podríamos considerarlo la causa de la muerte) o post-mortem, pero sin duda podemos descartar que se trate de una 
medida práctica llevada a cabo tras la muerte del sujeto con el objetivo de reducir su tamaño y hacerlo adecuado a las dimensiones de la fosa, ya que en los ejemplos que contamos ésta tiene espacio suficiente para albergar los restos de un individuo completo en conexión anatómica, y es mayor que la documentada para la mayoría de los enterramientos múltiples documentados

Es de destacar, además, que, a diferencia del resto de tipos, las fosas de inhumación de estos enterramientos no parecen haber sido excavada ex profeso para albergar a los fallecidos, ya que los restos humanos aparecieron sobre un nivel de relleno que indica que la colmatación de las estructuras ya había comenzado a producirse cuando se depositaron en ellas los cuerpos (parte de los mismos), mientras que en el resto de casos, los inhumados se depositaron directamente sobre el suelo de la fosa.

Entre las tumbas campaniformes encontramos enterramientos individuales, colectivos y dobles, si bien es predominante la inhumación individual. Ésta es la única forma documentada para los enterramientos en fosa al aire libre, que, además, es el tipo más numeroso de la región de Madrid, mientras que los enterramientos en fosa dentro de poblado y los enterramientos en covacha o hipogeo presentan un porcentaje del 50 por ciento para las inhumaciones individuales. Los enterramientos dentro de monumentos megalíticos no son representativos, puesto que sólo tenemos un caso, y desconocemos si se trata de una inhumación individual o colectiva.

Observamos, por tanto, que igual que ocurre en el caso de los enterramientos no-campaniformes, la inhumación individual es la más abundante, y, además, que ésta se vincula de manera exclusiva a un tipo específico de enterramiento: el realizado en fosa al aire libre, que es el único tipo que no se encuentra asociado a estructuras de habitación y que, por tanto, permanece fuera del área ocupada por el asentamiento con el que guardaría relación. No obstante, hay que tener en cuenta que la mayor parte de estas tumbas no se han localizado mediante una excavación en extensión y son fruto de hallazgos casuales, por lo que debemos tomar estos datos con cautela y no descartar la posibilidad de que en algunos casos no se trate realmente de estructuras aisladas.

De cualquier manera, los paralelos para este tipo de enterramiento son muy numerosos, lo que consolida la inhumación en fosa al aire libre, aislada o separada de los lugares de habitación, como una forma típica de sepultura asociada a cerámicas campaniformes. El ejemplo más famoso de este tipo de tumba es Fuente Olmedo, y parece que en la Meseta Norte los enterramientos aislados son la práctica funeraria más característica (Delibes de Castro, 1977: 128). En la región de Madrid, la mayor parte de estos enterramientos son hallazgos antiguos, por lo que la información con la que contamos es escasa, si bien excavaciones recientes han permitido conocer algunos aspectos hasta hace poco ignorados por la investigación, como la existencia de cubriciones pseudotumulares formadas por piedras, generalmente cantos de río o nódulos de sílex, que cubren y cierran este tipo de tumbas, y que también encontramos en el resto de tipos. No se trata, por tanto, de tumbas "planas" ya que cuentan con una señalización exterior que permite conocer su ubicación y que les sirve de cierre.

La inhumación en fosa fuera de poblado difiere notablemente del resto de tipos de enterramiento en cuanto a su concepción, aunque tipológicamente no podamos distinguirla de la inhumación en fosa dentro de poblado. El hecho de situarse lejos del poblado, y no entre las estructuras de habitación y almacenaje, responde, en mi opinión, a una intencionalidad específica, que quizás tenga que ver con el control del paisaje y sus recursos. Se ha señalado que, frente a los enterramientos en megalito, con un claro papel de hito demarcador de territorio, las tumbas en fosa campaniformes no tendrían un papel destacado en el paisaje (Garrido Pena, 2000: 49-50), sin embargo, no podemos descartar la posibilidad de que estas tumbas aisladas, ubicadas cerca, pero a una distancia clara del lugar de asentamiento, constituyesen un mecanismo de legitimación de los derechos de explotación del territorio circundante al núcleo poblacional donde reside la comunidad. A diferencia de lo que ocurriría en momentos precedentes, donde el ritual colectivo podía servir como mecanismo de justificación para la apropiación de los recursos de un territorio por parte de los allí enterrados, ahora sería la inhumación individual de un personaje destacado dentro de la comunidad lo que legitimaría el control del paisaje por parte de estas comunidades.

Contar con dataciones absolutas de los enterramientos nos permitiría conocer si se trata de formas coetáneas a las tumbas en fosa dentro de 
poblado o si, por el contrario, responden a momentos diferentes. En el caso de que las fosas aisladas fuesen relativamente más antiguas que las ubicadas entre estructuras de habitación, tendríamos un argumento a favor de la hipótesis antes mencionada sobre su papel como elementos legitimadores del control territorial por parte de un grupo: su realización se habría llevado a cabo en un momento clave del proceso de implantación de la economía campesina, previo a su consolidación definitiva, cuando, siguiendo las tradiciones anteriores, seguía siendo importante el papel de la tumba como elemento justificador de los derechos de explotación del territorio. En ellas se habrían enterrado unos personajes destacados, que cumplirían la misma función que anteriormente había desempeñado el grupo enterrado de manera colectiva en cueva o megalito, representando a la comunidad y sus derechos sobre los recursos del entorno. El resto de miembros se enterrarían en tumbas excavadas entre las estructuras habitacionales, costumbre que seguiría en práctica durante todo el periodo, y es posible que estas tumbas aisladas, una vez consolidado el modo de vida campesino, perdiesen su significado, y que los personajes más destacados de la comunidad comenzasen a enterrarse, al igual que el resto, dentro del asentamiento.

Los enterramientos campaniformes ubicados dentro de poblado responden, a diferencia de los anteriores, a dos tipos: tumbas de fosa simple y tumbas de mayor complejidad arquitectónica, del tipo cuevas artificiales (Rivero Galán, 1988), como hipogeos o covachas.

La diferencia entre covachas e hipogeos radica en el tamaño y la complejidad arquitectónica de las estructuras, aunque que en ambos casos se trata de cámaras excavadas en el suelo en el interior de otras estructuras de mayor tamaño similares a cabañas. Ambos tipos pueden presentar un acceso escalonado, pero, mientras que las covachas se excavan en los zócalos de estas estructuras a modo de nichos subterráneos, los ejemplos de hipogeos que tenemos se localizan cerca de los límites de estas "cabañas", pero sin adosarse a ellos, y presentan una cámara subterránea de mayores dimensiones y gran monumentalidad arquitectónica (Blasco et al., en prensa).

Frente a la complejidad de este tipo de construcciones, las fosas simples no difieren en absoluto de las estructuras negativas tipo silo que se documentan en todos estos asentamientos, si bien suelen presentar una cubrición pseudotumular formada por acumulación de piedras, que serviría como elemento demarcador y referente para conocer la ubicación de la tumba. En ocasiones, estas tumbas pueden albergar un pequeño nicho lateral de proporciones muy modestas, que en nada se asemejan a las covachas descritas más arriba.

Tanto los hipogeos o covachas como las tumbas de fosa pueden contener enterramientos individuales como colectivos, a diferencia de lo que ocurre en el caso de las tumbas no-campaniformes entre las que predomina el rito de inhumación individual y las formas de enterramiento múltiple.

El enterramiento colectivo no simultáneo, documentado en dos enterramientos de Camino de las Yeseras y en la tumba 2 de fosa de La Salmedina (Berzosa y Flores, 2005: 483-484), responde al deseo de crear o mantener lazos entre las personas enterradas después de la muerte, e implica la manipulación de los restos humanos una vez ha comenzado o finalizado el proceso de putrefacción, como se deduce del estado de desconexión anatómica que presentan los esqueletos de los inhumados en estas condiciones. Aunque porcentualmente escasa, la práctica de la inhumación colectiva nos habla de la existencia de un rito específico y diferente al de la inhumación individual primaria, hasta hace poco considerada la única forma para las tumbas campaniformes (Garrido Pena, 2000: 67). Explicar el porqué de su convivencia con el enterramiento individual resulta complejo e imposible con el escaso número de ejemplos con los que contamos, no obstante, aunque pocos, estos casos nos permiten afirmar que el rito de inhumación "campaniforme" no se reduce a la inhumación individual, y que detrás de muchos enterramientos hay una serie de ritos muy complejos relacionados con la manipulación de los cuerpos.

\section{TUMBAS CON Y SIN AJUAR: LA ESTRUCTURA SOCIAL DE LAS COMUNIDADES DEL Calcolítico madrileño}

Partiendo de que existe una estrecha relación que entre estructura social e ideología y prácticas funerarias, un enterramiento debe considerarse como un acto intencionado en el que "todo responde a una selección no casual ni arbitraria sino determinada, a veces por las circunstancias, pero 
más frecuentemente por las creencias y requerimientos sociales" (Andrés Rupérez, 2003: 17). Las prácticas funerarias tienen, por tanto, un significado radicado en la estructura ideológica de las comunidades que las llevan a cabo, que manifiestan a través de ellas la conciencia de su pasado (Andrés Rupérez, 2003: 127).

Como hemos ido viendo, podemos corroborar la existencia de cambios o transformaciones en el mundo funerario de las comunidades que habitaron la región de Madrid a lo largo del Calcolítico, que se traducen en el abandono del enterramiento colectivo en cueva por la inhumación en fosa cerca o dentro de áreas de habitación, mayoritariamente individual. Para Díaz-del-Río esta evolución de los patrones funerarios "está asociada al desarrollo de las relaciones de producción y reproducción social", que implican la primera manifestación de la individualidad como resultado de la posibilidad de ciertos individuos de ganar una posición preeminente o distinguida dentro de la sociedad "mediante la manipulación o intermediación en unas relaciones sociales intergrupales que requieren una nueva renegociación de equilibrios tras la creciente territorialización del paisaje" (Díaz-del-Río, 2001: 163). Estaríamos asistiendo, por tanto, al nacimiento de las primeras diferencias sociales que se reflejan en el ámbito funerario en la implantación de la tumba individual frente a la colectiva y en la presencia de objetos destacados formando parte de los ajuares de ciertos personajes.

Se ha señalado que el paso de la inhumación colectiva a la individual se produce de manera gradual "en términos de un incremento en la diferenciación social, del surgimiento de conjuntos materiales con propósitos específicos, o del desarrollo de una nueva ideología que persigue la justificación de la desigualdad social" (Thomas, 2005: 107), pero que la aparición de la tumba individual se produzca de forma casi simultánea a la aparición de la cerámica campaniforme no quiere decir que ésta sea consecuencia de la anterior ni viceversa, sino que ambos aspectos son el resultado de toda una serie de cambios socioeconómicos que se han producido en el seno de estas comunidades calcolíticas. Como se deduce de yacimientos como Camino de las Yeseras, la introducción de la cerámica campaniforme no supuso ningún cambio abrupto en las formas de vida ni en las prácticas funerarias de sus habitantes, de manera que no podemos considerarla el síntoma ni la causa de una forma específica de organización social (Thomas, 2005: 112 y 119). Y esto mismo puede hacerse extensivo a otras zonas de la Meseta, donde necrópolis como la de Huecas, en Toledo, demuestran cómo entre el 3400 y el 1900 a. C. se perpetúan las mismas prácticas funerarias y la cerámica campaniforme se añade al resto de objetos destacados como un valor de prestigio más que sirve para justificar la posición preeminente de ciertos individuos (Bueno et al., 2005: 67-70 y 86-86).

Las incipientes diferencias sociales que comienzan a perfilarse en este Calcolítico Pleno quedarían evidenciadas en el registro funerario a través de la presencia de ajuares en los que se amortizan determinados objetos y materias primas (cerámicas campaniformes, oro, marfil, metal) de manera desigual entre unas tumbas y otras.

Dentro de las tumbas campaniformes, existen diferencias en la composición de los ajuares que podrían señalar distintos grados de riqueza, y que constituyen un importante indicador de la existencia de un acceso diferenciado a determinados recursos por parte de los miembros de una sociedad, más aún si tenemos en cuenta que el ajuar campaniforme en sí se interpreta como un lote de objetos de prestigio pertenecientes a un grupo de élite, que está detrás de las transformaciones ideológicas que están cambiado las relaciones individuo-grupo (Garrido Pena, 2000: 62 y 66). Ajuares tan ricos como el de Arenero de Miguel Ruiz, o el de los hipogeos de Camino de las Yeseras (Liesau et al., 2008: 113-116) nos indican la existencia de una serie de personajes que poseen un papel importante dentro de la comunidad, que es celebrado en el momento de su muerte y entierro; y que junto a estos personajes, existen otros cuyas tumbas presentan un ajuar compuesto por elementos de menor riqueza y singularidad, que nos hablarían de un grupo social destacado, pero con un acceso más restringido a los mismos bienes de prestigio.

En el caso de los enterramientos con ajuares campaniformes, éstos no son el único indicador de desigualdades sociales, sino que, como han demostrado los hallazgos de Camino de las Yeseras, la propia tumba constituye un factor determinante a la hora de reconstruir la estructura social de estas comunidades. Así, encontramos hipogeos y covachas excavadas en el suelo de complejidad arquitectónica notable, que reflejan 
una clara intención de monumentalidad y son indicativos de un gasto en tiempo y energía superior a la puesta en marcha para realizar las tumbas de fosa simple. Si tenemos en cuenta, además, que a este tipo de tumbas suntuosas les corresponden ajuares igualmente ricos, del que el mejor ejemplo sea, quizás, el enterramiento en hipogeo del área funeraria 1 de Camino de las Yeseras, formado por 22 cuentas tubulares y dos placas trapezoidales de oro, una veintena de cuentas bicónicas de marfil, varios botones de marfil con perforación en "V" y una cazuela campaniforme de estilo Ciempozuelos con un friso de ciervos y ciervas esquemáticas incisos en el cuello (Liesau et al., 2008: 114), podemos afirmar, casi con total seguridad, que existen diferencias de tipo social cuantificables en el registro funerario campaniforme de la región de Madrid, en contra de lo que sostiene Díaz-del-Río cuando escribe que "los ajuares y el trabajo invertido en las tumbas no parecen corroborar una creciente diferenciación social entre los inhumados" (Díaz-del-Río, 2001: 292).

Esta hipótesis cobra aún más fuerza si tenemos en cuenta que muchos de estos enterramientos campaniformes son coetáneos a los denominados no-campaniformes, y que, en Camino de las Yeseras ambas formas funerarias comparten un mismo espacio. En este mismo sentido, debemos tener en cuenta que en los casos de enterramientos individuales en los que no se han documentado cerámicas campaniformes dentro de la tumba tampoco se ha hallado ningún otro elemento de ajuar. Dejando a un lado los enterramientos múltiples, son las tumbas campaniformes las únicas que presentan ajuar, y si la explicación a la coexistencia de enterramientos con y sin campaniforme, no reside, como hemos visto, en factores cronológicos ni culturales, debemos buscar explicaciones en factores de tipo social, relacionados con los procesos de diferenciación que se están produciendo en esta etapa.

Según Teresa Andrés Rupérez, el hecho mismo del enterramiento supone, en cierto sentido, la posibilidad de una vida estable en un punto concreto o, al menos, la existencia de un concepto de posesión territorial (Andrés Rupérez, 2003: 20). Siguiendo esta tesis, la idea de derechos sobre un territorio estaría presente en nuestra región desde el Neolítico, cuando documentamos las primeras manifestaciones funerarias (Arenero de Valdivia), coincidiendo con la implantación de un modelo económico agrícola, aún no consolida- do. Durante el Calcolítico Inicial, en la región de Madrid las comunidades prehistóricas van a utilizar las prácticas funerarias como forma de legitimar y justificar los derechos de explotación sobre los recursos del entorno en el que se asientan, realizando enterramientos de carácter colectivo en cuevas, cerca de las zonas de asentamiento o en sus inmediaciones, para resaltar los lazos de unión entre los miembros del grupo y vincularse con sus antepasados. Ya desde el Neolítico Final se estaría produciendo una expansión paulatina de los poblados de fondo de valle, proceso que se consolidaría a partir de la segunda mitad del III milenio a. C., cuando parece que se abandona el asentamiento en cueva y se produce una eclosión de los poblados de hoyos ubicados en las llanuras aluviales y las vegas de los ríos madrileños, que reflejan una economía plenamente agraria basada en los cultivos cerealísticos y hortícolas y en la ganadería ovicaprina, vacuna y porcina (Díaz-delRío, 2001: 310-311).

Quizás los poblados como El Espinillo o Las Matillas, a los que podemos sumar Camino de las Yeseras, puedan reflejar una distribución que remita a una organización comunitaria del espacio (Díaz-del-Rio, 2001: 313), pero los enterramientos constituyen un argumento a favor del desarrollo progresivo de desigualdades sociales que no podemos ignorar. Estas desigualdades no tienen por qué ser el reflejo de la implantación de un sistema de "poder coercitivo", pero evidencian la capacidad de ciertos individuos y de sus familias para acumular bienes de prestigio y amortizarlos a modo de ajuar en el momento de la muerte de uno de sus miembros.

Frente a las tumbas sin ajuar, tenemos las sepulturas campaniformes, en las que se amortizan cantidades importantes de estas cerámicas que, a veces, son acompañadas de otros objetos de indiscutible valor, como el oro o el marfil, y que pueden presentar características arquitectónicas especiales, de manera que las diferencias de riqueza entre unas y otras son evidentes. Pero no sólo existe una dicotomía entre tumbas con y sin ajuar, sino que dentro de los enterramientos con ofrendas se dan también diferentes grados de riqueza, de lo que se deduce la existencia de una estructura social más o menos jerarquizada.

No conocemos la naturaleza de estas desigualdades sociales, pero sabemos que éstas se expresan por medio del consumo de objetos de prestigio y símbolos rituales, entre los que podría estar 
la cerámica campaniforme (Shennan, 1982: 156, Delibes de Castro, 1977: 90, Garrido Pena, 2000: 62-63), relacionada con ceremonias de manipulación y consumo de bebidas y alimentos (Garrido Pena, 2000: 70 y 75-79), y con un alto valor simbólico, que reflejaría la posición social del fallecido (Thomas, 1991: 34-35). La muestra demográfica de las tumbas campaniformes madrileñas nos indica que el acceso a estos bienes (cerámicas campaniformes) no estaba restringido por cuestiones de sexo o edad, de lo que se deduce que la posición social de los inhumados podría ser de carácter hereditario (Andrés Rupérez, 2003: 25). Hablaríamos entonces de linajes, o de grupos familiares más o menos amplios, que poseerían una serie de privilegios basados en el reconocimiento social de sus lazos de sangre por parte del resto de miembros de la comunidad, con los que podrían acceder a una serie de objetos y elementos de prestigio y amortizarlos en sus tumbas. Las diferencias de riquezas entre unos enterramientos campaniformes y otros podrían estar determinadas por el desarrollo de distintos roles o por la posición de los individuos dentro del grupo privilegiado.

La existencia de linajes o de familias privilegiadas quedaría constatada, además, por la existencia de áreas funerarias a modo de panteones como las halladas en Camino de las Yeseras, dentro de las cuales se realizan varios enterramientos de características excepcionales, como son los hipogeos y covachas, tanto por su arquitectura como por sus ajuares; y por la existencia de enterramientos infantiles con ajuares campaniformes (Liesau et al., 2008: 113-114).

\section{Bibliografía}

ANDRÉS RUPÉREZ, M. T. (1989-1990): “Sepulturas calcolíticas de inhumación múltiple simultánea en la cuenca media del Ebro". Caesaraugusta 6667, 13-27.

ANDRÉS RUPÉREZ, M. T. (2003): "El concepto de la muerte y el ritual funerario en la Prehistoria". Cuadernos de Arqueología de la Universidad de Navarra 11, 13-36.

BERMÚDEZ DE CASTRO, J. M. Y JULIA PÉREZ, P. (1984): "Restos humanos de la cueva del Cerro de Juan Barbero (Tielmes de Tajuña, Madrid): estudio antropológico". Trabajos Prehistoria 41, 113-119.
BERZOSA DEL CAMPO, R. Y FLORES DÍAZ, M. (2005): "El conjunto funerario campaniforme del Vertedero de La Salmedina (Distrito Villa de Vallecas, Madrid)". En ROJO GUERRA, M. A.: El Campaniforme en la Península Ibérica y su contexto europeo. Universidad de Valladolid, 481-490. Valladolid.

BLASCO BOSQUED, $\quad \mathrm{M}^{\mathrm{a}}$. C. (1997): "Manifestaciones funerarias de la Edad del Bronce en la Meseta”. Saguntum 30, 173-190.

BLASCO BOSQUED, Ma . C. (1998): "El Horizonte Campaniforme y la Edad del Bronce en Madrid". Boletín de la Asociación Española de Amigos de la Aarqueología 38, 147-166.

BLASCO BOSQUED, Mª C. Y RECUERO, V. (1994): "Inventario general de yacimientos". En Blasco Bosqued, $\mathrm{M}^{\mathrm{a}}$. C.: El Horizonte Campaniforme en la Región de Madrid en el Centenario de Ciempozuelos. Dep. de Prehistoria y Arqueología, UAM, 13-46. Madrid.

BLASCO, Ma . C., LIESAU, C., RÍOS, P., BLANCO, J.F., ALIAGA, R., MORENO, E. Y DAZA, A. (en prensa): "Kupferzeitliche siedlungsbestattungen mit glockenbecher- und prestigebeigaben aus dem grabenwerk von El Camino de las Yeseras (San Fernando de Henares, Prov. Madrid). Untersuchungen zur typologie des grabritus und zu dessen sozialer symbolik". Madrider Mitteilungen 50.

BUENO RAMÍREZ, P.; BARROSO BERMEJO, R.; DE BALBÍN BEHRMANN, R. (2005): "Ritual campaniforme, ritual colectivo: la necrópolis de cuevas artificiales del Valle de las Higueras, Huecas, Toledo". Trabajos de Prehistoria 62 (2), 67-90.

CRIADO BOADO, F. (1989): "Megalitos, espacio, pensamiento". Trabajos de Prehistoria 46, 75-98.

DE MARRAIS, E., CASTILlO, L. J.; EARLE, T. (1996): "Ideology, materialization, and Power strategies". Current Anthropology 37 (1), 97-100.

DELIBES DE CASTRO, G. (1977): El vaso campaniforme en la Meseta Norte española. Valladolid.

DELIBES DE CASTRO, G. (1978): “Una inhumación triple de Facies Cogotas I en San Román de la Hornija (Valladolid)". Trabajos de Prehistoria $35,225-247$.

DÍAZ-DEL-RÍO ESPAÑOL, P. (1996): "En enterramiento colectivo de El Rebollosillo (Torrelaguna)". Reunión de Arqueología Madrileña, 98-200. Madrid. 
DÍAZ-DEL-RÍO ESPAÑOL, P. (2001): La formación del paisaje agrario: Madrid en el III y II milenio $B C$, Arqueología, Paleontología y Etnografía de la Comunidad de Madrid 9.

FABIÁN GARCÍA, J. F. (1993): "La secuencia cultural durante la Prehistoria Reciente en el Sur de la Meseta Norte española". Actas $1^{\circ}$ Congresso de Arqueología Peninsular (Porto, 12-18 de Outubro de 1993), 145-176.

FABIÁN GARCÍA, J. F. (1995): El aspecto funerario durante el calcolítico y los inicios de la Edad del Bronce en la meseta norte, Salamanca.

FABIÁN GARCÍA, J. F. (2006): El IV y el III milenio AC en el Valle Amblés (Ávila), Monografías de Arqueología de la Junta de Castilla y León $n^{\circ} 5$.

GARRIDO PENA, R. (2000): El Campaniforme en la Meseta Central de la Península Ibérica (c. 25002000 AC), BAR Internacional Series 892.

GARRIDO, R.; ROJO, M. A. Y GARCÍAMARTÍNEZ, I. (2005): "El Campaniforme en la Meseta central de la Península Ibérica”. En ROJO GUERRA, M. A.: El Campaniforme en la Península Ibérica y su contexto europeo, Universidad de Valladolid, 411-435. Valladolid.

JIMÉNEZ GUIJARRO. J. (2000): “Megalithic tombs and chalcolithic settlement in the Guadarrama mountains: following ancient roads, marking out territory". Journal of Iberian Archaeology 2, 99109.

JIMÉNEZ GUIJARRO, J. (2001): "El yacimiento de Valdivia (Madrid). Nuevos elementos materiales para la interpretación del Neolítico del interior peninsular". Estudios de Prehistoria y Arqueología Madrileños 11, 59-68.

JORDÁ , J. F. Y MESTRES, J. S. (1999): “El enterramiento calcolítico precampaniforme de Jarama II: una nueva fecha radiocarbónica para la Prehistoria Reciente de Guadalajara y su integración en la cronología de la región”, Zephyrus 52, 175-190.

LIESAU, C., BLASCO, C., RÍOS, P., VEGA, J., MENDUINAA, R., BLANCO, J. F., BAENA, J., HERRERA T., PETRI, A. Y GÓMEZ, J.L. (2008): "Un espacio compartido por vivos y muertos: el poblado calcolítico de fosos de Camino de las Yeseras". Complutum 19, 97-120.

LOSADA, H. (1976): "El dolmen de Entretérminos". Trabajos de Prehistoria 33, 109-221.
MARTÍNEZ NAVARRETE, Mª I. (1984): “El comienzo de la metalurgia en la provincia de Madrid: la Cueva y el Cerro de Juan Barbero (Tielmes, Madrid)". Trabajos de Prehistoria 41, 17-89.

MARTÍNEZ NAVARRETE, Ma . I. (1987): "Los primeros periodos metalúrgicos". En VV.AA.: 130 años de Arqueología Madrileña, Madrid, 60-81.

MUÑOZ LÓPEZ-ASTILLEROS, K. (1999): “La Prehistoria Reciente en el Tajo Central (Cal. V-I milenio A.C.)". Complutum 10, 91-122.

MUÑOZ, K.; GARCÍA, T.; E IZQUIERDO, D. (1995): "Aportaciones al estudio de la Edad del Cobre en la Cuenca Media del Río Tajo". Boletín del Seminario de Estudios de Arte y Arqueología LXI, 31-50.

RIAÑO, F., DE LA RADA, J. Y CATALINA, J. (1894): "Hallazgo prehistórico de Ciempozuelos", en Boletín de la Real Academia de la Historia 25, 436-450.

RIVERO GALÁN, E. (1988): Análisis de las cuevas artificiales en Andalucía y Portugal. Publicaciones de la Universidad de Sevilla. Sevilla.

RUBIO DE MIGUEL, Mª I. (2001-2002): “El mundo funerario neolítico peninsular. Algunas reflexiones sobre su trasfondo social". Anales de Prehistoria y Arqueología 16-17, 53-66.

SHENNAN, S. J. (1982): "Ideology, change and the European Early Bronze Age". En HodDER, I.: Symbolic and Structural Archaeology. Cambridge University Press. Cambridge, 155161 .

THOMAS, J. S. (1991): "Reading the body: beaker burial practices in Britain”. En GARwOOD, P. et al.: Sacred and Profane: Archaeology, Ritual and Religion. Oxford, 33-42.

THOMAS, J. S. (2005): “¿Ceremonia de los Jinetes? De las tumbas megalíticas a los enterramientos campaniformes en la Europa prehistórica". En ROJO GUERRA, M. A.: El Campaniforme en la Península Ibérica y su contexto europeo. Universidad de Valladolid, 107-121. Valladolid. 